\title{
BMJ Open Consequences of maternal morbidity on health-related functioning: a systematic scoping review
}

\author{
Kazuyo Machiyama, ${ }^{1}$ Atsumi Hirose, ${ }^{2}$ Jenny A Cresswell, ${ }^{1}$ Maria Barreix, ${ }^{3}$ \\ Doris Chou, ${ }^{3}$ Nenad Kostanjsek, ${ }^{4}$ Lale Say, ${ }^{3}$ Véronique Filippi ${ }^{1}$
}

To cite: Machiyama $\mathrm{K}$, Hirose A, Cresswell JA, et al. Consequences of maternal morbidity on health-related functioning: a systematic scoping review. BMJ Open 2017;7:e013903. doi:10.1136/ bmjopen-2016-013903

- Prepublication history and additional material are available. To view these files please visit the journal online (http://dx.doi.org/ 10.1136/ bmjopen-2016-013903)

Received 20 August 2016 Revised 1 April 2017 Accepted 11 April 2017

A Check for updates

${ }^{1}$ Faculty of Epidemiology and Population Health, London School of Hygiene and Tropical Medicine, London, UK

${ }^{2}$ Department of Public Health Sciences, Karolinska Institutet, Stockholm, Sweden

${ }^{3}$ Department of Reproductive Health and Research, World Health Organization, UNDP/ UNFPA/UNICEF/WHO/World Bank Special Programme of Research, Development and Research Training in Human Reproduction (HRP), Geneva, Switzerland ${ }^{4}$ Department of Health Statistics and Informatics, World Health Organization, Classification, Terminology and Standards, Geneva, Switzerland

\section{Correspondence to} Dr Kazuyo Machiyama; kazuyo.machiyama@|shtm. ac.uk

\section{ABSTRACT}

Objectives To assess the scope of the published literature on the consequences of maternal morbidity on health-related functioning at the global level and identify key substantive findings as well as research and methodological gaps.

Methods We searched for articles published between 2005 and 2014 using Medline, Embase, Popline, CINAHL

Plus and three regional bibliographic databases in January 2015.

Design Systematic scoping review

Primary outcome Health-related functioning

Results After screening 17706 studies, 136 articles were identified for inclusion. While a substantial number of papers have documented mostly negative effects of morbidity on health-related functioning and wellbeing, the body of evidence is not spread evenly across conditions, domains or geographical regions. Over $60 \%$ of the studies focus on indirect conditions such as depression, diabetes and incontinence. Health-related functioning is often assessed by instruments designed for the general population including the 36-item Short Form or disease-specific tools. The functioning domains most frequently documented are physical and mental; studies that examined physical, mental, social, economic and specifically focused on marital, maternal and sexual functioning are rare. Only 16 studies were conducted in Africa.

Conclusions Many assessments have not been comprehensive and have paid little attention to important functioning domains for pregnant and postpartum women. The development of a comprehensive instrument specific to maternal health would greatly advance our understanding of burden of ill health associated with maternal morbidity and help set priorities. The lack of attention to consequences on functioning associated with the main direct obstetric complications is of particular concern.

Review registration CRD42015017774

\section{INTRODUCTION}

Maternal morbidity occurs frequently, but is poorly studied. At present, there are an estimated 27 million episodes of direct complications that occur annually. ${ }^{1}$ The burden of maternal morbidity is much larger than this estimate when indirect complications and

\section{Strengths and limitations of this study}

- Extensive scoping review identifying key substantive findings and research and methodological gaps on the consequences of maternal morbidity on healthrelated functioning at the global level.

- The scoping review that includes a full range of maternal morbidities during pregnancy, childbirth, and postpartum, and assesses the impact on physical, mental, economic and social functioning.

- A quantitative meta-analysis could not be conducted given the wide range of conditions, tools, measures and timing of assessment of functioning.

long-term sequelae are added to the calculation, some of which can be particularly common. ${ }^{12}$ For example, anaemia affects 32 million (a range of 28-36 million) pregnant women per year according to a model. ${ }^{3}$ However, these estimates on the epidemiology of maternal morbidity are based on varying criteria, which has prompted the establishment of the World Health Organization (WHO) Maternal Morbidity Working Group (MMWG) to develop a standard definition and measurement criteria.

By defining maternal morbidity as 'any health condition attributed to and/or complicating pregnancy and childbirth that has a negative impact on the woman's wellbeing and/or functioning, ${ }^{4}$ the WHO MMWG emphasises the need for comprehensiveness in the evaluation of the maternal morbidity burden. Concurrently, global attention in policies such as the strategies toward Ending Preventable Maternal Mortality (EPMM) is shifting from focusing on maternal mortality, which is decreasing, to focusing on women who survive and addressing their morbidities. ${ }^{5}$ Indeed, while there is increased focus on describing the levels and patterns of maternal morbidity, ${ }^{16-8}$ the extent to which this morbidity collectively impacts upon 
women's health-related functioning is poorly understood. ${ }^{9} 10$

Studies in the USA and Canada have demonstrated that pregnancy itself limits aspects of women's functioning. ${ }^{112}$ Changes in physical functioning from first to second trimesters, and from second to third trimesters have been observed among women with uncomplicated pregnancies. ${ }^{11}{ }^{13-15}$ While acute complications soon disappear after childbirth for most women, others may develop sequelae and experience certain health conditions, such as fatigue, sleep-related problems, pain, and concerns about sexual activities, depression, anxiety, haemorrhoids and constipation. These often last well over the 6 weeks of puerperium ${ }^{16}{ }^{17}$ and have even been documented to peak around 6 months after delivery before declining. ${ }^{18}$ Therefore, the additional effects of maternal morbidity on women's functioning are important to comprehend, particularly with respect to differentials in patterns, duration, size and risk factors. ${ }^{4}$

The effects of maternal morbidity extend beyond the physical or the psychological to also social and economic. In Sri Lanka, 90\% of pregnant women reported at least one episode of perceived ill health during pregnancy and $26 \%$ of them reported that they required another person to replace them in their routine activities because they were unwell. ${ }^{19}$ One hypothesis is that the more severe the maternal morbidity experienced the more likely the negative consequences. A handful of recent cohort studies have shown that women diagnosed with severe obstetric complications (including 'near-miss') had a higher risk of health, social and economic adversities persisting well beyond pregnancy, and the 6-week postpartum period compared with women with uncomplicated childbirth. ${ }^{20-28}$

The most comprehensive source of summarised evidence to date on the consequences of maternal morbidity is a systematic review on health-related quality of life (HRQOL) after childbirth. ${ }^{29}$ This review of 66 articles concentrated on the physical, social and psychological domains. While it did not focus specifically on the effects of maternal morbidity, the authors found that urinary incontinence and HIV were negatively correlated with quality of life (QOL), and that depression had an impact on health status scores such as those measured by the 36-item Short Form (SF-36). ${ }^{29}$ More recently, Andreucci et al reviewed the effects of maternal morbidity on sexual dysfunction. Despite the substantial methodological heterogeneity between studies, they found an association between perineal injuries with increased dyspareunia and delayed resumption of sex after childbirth. ${ }^{30}$ In contrast, a recent cohort study shows sexual function 3 months after delivery, for women who had severe maternal morbidity, was similar to the level of the control group. ${ }^{31}$ The effects of other maternal morbidities on health-related functioning and QOL have rarely been investigated in systematic reviews. ${ }^{29}$ Additionally, studies such as those mentioned above focus on the impact of a morbidity with a limited anatomical interpretation (ie, a perineal injury's impact on a woman's sexual life), rather than a more holistic view on how women's everyday abilities may be impacted (eg, her overall relationship with her partner, not limited to sex, or her ability to care for the child or resume her economic activity).

\section{Concepts and measurement of health-related functioning and QOL/well-being}

The difference between health-related functioning and HRQOL may be ambiguous, as there is overlap. Functioning and disability (the negative correlate of functioning) are conceptualised by the International Classification of Functioning, Disability and Health (ICF). The ICF classified functioning and disability into three levels: at the level of body or body part, the whole person, and the whole person in a social context. Disability is defined as 'the outcome of the interaction between a person with an impairment and the environmental and attitudinal barriers he or she may face. ${ }^{32}$ The concept of disability is not restricted to impairment of body function and structures. It encompasses loss or limited capacity to execute a task or action by individual (eg, eating, standing, walking), and to be involved in a life situation in an environment (eg, employment). The ICF is also the international classification and metrics for organising and reporting health and disability data which enables us to use common metrics over time and space.

QOL and the more specific notion of HRQOL are also widely used to understand how diseases or the absence of disease influences the lives of individuals. It relates to the broader concept of well-being than the concept of health-related functioning, and encompasses perception of life satisfaction which is shaped by many factors including health. ${ }^{33}$ Although there are many definitions, QOL has been defined by WHO as the 'individual's perception of their position in life in the context of the culture and value systems in which they live and in relation to their goals, expectations, standards and concerns. ${ }^{33}$ As explicitly stated in the WHO's definition, QOL gives weight to individual's perception of the ability to lead a fulfilling life. ${ }^{34}$ The concept of HRQOL encompasses aspects of QOL which can clearly affect health or be affected by health conditions, and is defined as 'optimum levels of mental, physical role and social functioning, including relationships and perceptions of health, fitness, life satisfaction and wellbeing. ${ }^{35}$ In contrast, health-related functioning does not focus on individual's perception or subjective well-being. It can be based on established comparable parameters such as the ICF, and provide more precise information on level of functioning than HRQOL. ${ }^{36}$ Effective healthcare planning and management needs comparable data on level of functioning, which predict work performance, return to work potential, likelihood of social integration or receipt of disability benefits. ${ }^{32}$

Health-related functioning and HRQOL are important patient-reported health outcomes which have been used in other sectors of public health to measure the 
effectiveness of intervention or to allocate resources. ${ }^{37}$ However, most of the existing studies of maternal health focus on mortality and morbidity, and there is limited research that aims to assess women's QOL as a primary outcome. ${ }^{38}$ The guidelines on postnatal care up to 8 weeks after birth developed by the British National Institute for Health and Care Excellence recommend health professionals to check women's physical, emotional and social well-being. ${ }^{39}$ More complete data on maternal morbidities and consequences would contribute to setting priorities for reducing the burden of maternal ill health.

Nonetheless, measurement of health-related functioning and QOL is complex. While these concepts are concerned with individual's perceptions of personal health, well-being and satisfaction with health status and life, predetermined quantitative scales are often applied. There are a number of standardised generic instruments used to measure functioning and QOL. For instance, the SF-36 is one of the most commonly used tools for assessing functioning and well-being, and often employed to assess the performance of new instruments. The SF-36 has been validated among women in early pregnancy. ${ }^{40}$ However, women during late pregnancy or postpartum were not taken into account during the instrument development process, and indeed, no generic tools assessed their reliability, validity or responsiveness for these specific populations in different settings. ${ }^{41}$ Tools developed specifically for use in relation to maternal health include the Inventory of Functional Status After Childbirth (IFSAC), which focuses on social functioning, ${ }^{42}$ the Mother Generated Index, which is self-created by each individual woman to assess the effect of having a new baby on her QOL, ${ }^{43}$ and the Maternal Postpartum Quality of Life tool (MAPP-QOL) with emphasis on women's satisfaction with various areas of their life during early postpartum. ${ }^{44}$ All of these tools are concerned with events in the postpartum period in relation to the experience of childbirth, were validated in relatively homogenous and small study populations and have been applied infrequently. ${ }^{41}$

As members of the MMWG, we conducted a systematic scoping review of the published literature on the shortterm and long-term consequences of maternal morbidity on health-related functioning to assess the scope of the literature at the global level, identify key substantive findings as well as research and methodological gaps. ${ }^{45}$ In this paper, we critically appraise the available literature with particular interest in the type of conditions studied, the tools used, the range of domains considered, the timing of assessment, the study design and geographical coverage. We then qualitatively assess the range of domains studied and the effects of morbidity. Finally, we focus on two conditions, hyperemesis gravidarum and incontinence during pregnancy to illustrate characteristics of included studies and the impacts on health-related functioning.

\section{METHODS}

\section{Data sources and search strategy}

We adapted a WHO generic protocol used in all the systematic reviews conducted by members of the MMWG. ${ }^{10} 46$ The protocol is registered in PROSPERO (CRD42015017774, http://www.crd.york.ac.uk/PROSPERO/display_record.asp?ID=CRD42015017774). We searched relevant articles published between 1 January 2005 and 31 December 2014 using a structured search strategy in four bibliographic electronic databases (Medline, Embase, Popline, CINAHL Plus) and three WHO regional databases (Latin American and Caribbean Center on Health Sciences Information, African Index Medicus and the West Pacific Region Index Medicus) in January 2015. We focused on the literature published in 2005 or later given the size of literature and because we expect to have more papers relevant to our aim in recent years in view of the fact that the ICF that provides a comprehensive framework of health-related functioning was introduced by WHO only in 2002.

A full search strategy for each database was developed using thesaurus (including $\mathrm{MeSH}$ ) and free-text terms for maternal morbidity and health-related functioning. We added search terms relating to individual maternal health conditions based on the maternal morbidity matrix constructed by Chou et al. ${ }^{4}$ The outcome for this review, health-related functioning, encompasses multiple dimensions, such as cognitive, physical, mental, social and economic functions, and the terms relating to each of these concepts were included in the search strategy. While the primary focus of the systematic scoping review is the negative impact of morbidity on health-related functioning, HRQOL findings (and other concepts capturing the consequences of morbidity) were added to make sure that we captured all of the relevant literature. This is also because the WHO maternal morbidity definition includes both the terms 'wellbeing' and 'functioning'. The search strategy is available in online supplementary appendix 1 .

\section{Inclusion and exclusion criteria}

All studies were eligible for inclusion if they met the following criteria: (1) the study population included at least 30 women who experienced maternal morbidity during pregnancy, childbirth or 1 year after delivery or spontaneous abortion; and (2) results included quantitative data on health-related functioning by maternal morbidity status. Thus, we included any studies which assessed outcome, that is, health-related functioning, at any time after delivery because we aimed to examine long-term as well as short-term consequences of maternal morbidities. We excluded intervention studies if respondents were all treated and the primary objective of the study was comparisons of treatment. Studies with no primary data were excluded. All other study types were eligible. There were no language restrictions.

Induced abortion, stillbirth and preterm birth were excluded from this review when they were the only exposure in a study. While these outcomes may be associated 
with maternal complications, they are not exclusively maternal morbidities. Intimate partner violence, substance use, smoking, alcohol, female genital mutilation and multiple pregnancies were also not considered maternal morbidities for the purposes of this review, though these factors increase the risk of maternal morbidities. A number of studies assessed depression or depressive symptoms as consequences of maternal morbidities using screening tools such as the Edinburgh Postnatal Depression Scale or the 9-item Patient Health Questionnaire. Although individual questionnaire items in some of these tools imply women with the condition have low level of functioning, we excluded studies that did not explicitly report on mental functioning as an outcome as it was not possible to separate characteristics and severity of depressive symptoms, and level of functioning. Studies that assessed any of the following: practice of breastfeeding, self-efficacy, locus of control, confidence, competence, self-esteem, life satisfaction and social support, as an outcome but did not assess this in the context of women's health-related functioning were not included. Although maternal-infant interaction was sometimes chosen as an outcome in studies on depression, this review excluded studies if they did not explicitly examine woman's ability to care for her child as functioning.

\section{Selection and data extraction}

Four authors (KM, AH, JAC, VF) with help from a research assistant (LP) screened titles and abstracts. At the beginning of the screening, a pilot test of 100 papers by three reviewers (KM, AH, JAC) was conducted to help achieve inter-rater reliability. Evaluation of full-text reports was done by four authors (KM, AH, JAC, VF), with reasons for exclusion recorded for excluded papers. Data extraction from the full-text report was conducted by a single author for each retained paper (KM, AH, JAC, VF, MB, DC); information was extracted on: location of study, study dates, study design, study population, sampling, case definition of maternal morbidity, methods of measurement of health-related functioning and the timing of the assessment, and measures of functioning by morbidity status. When a study assessed multiple maternal morbidities or examined health-related function several

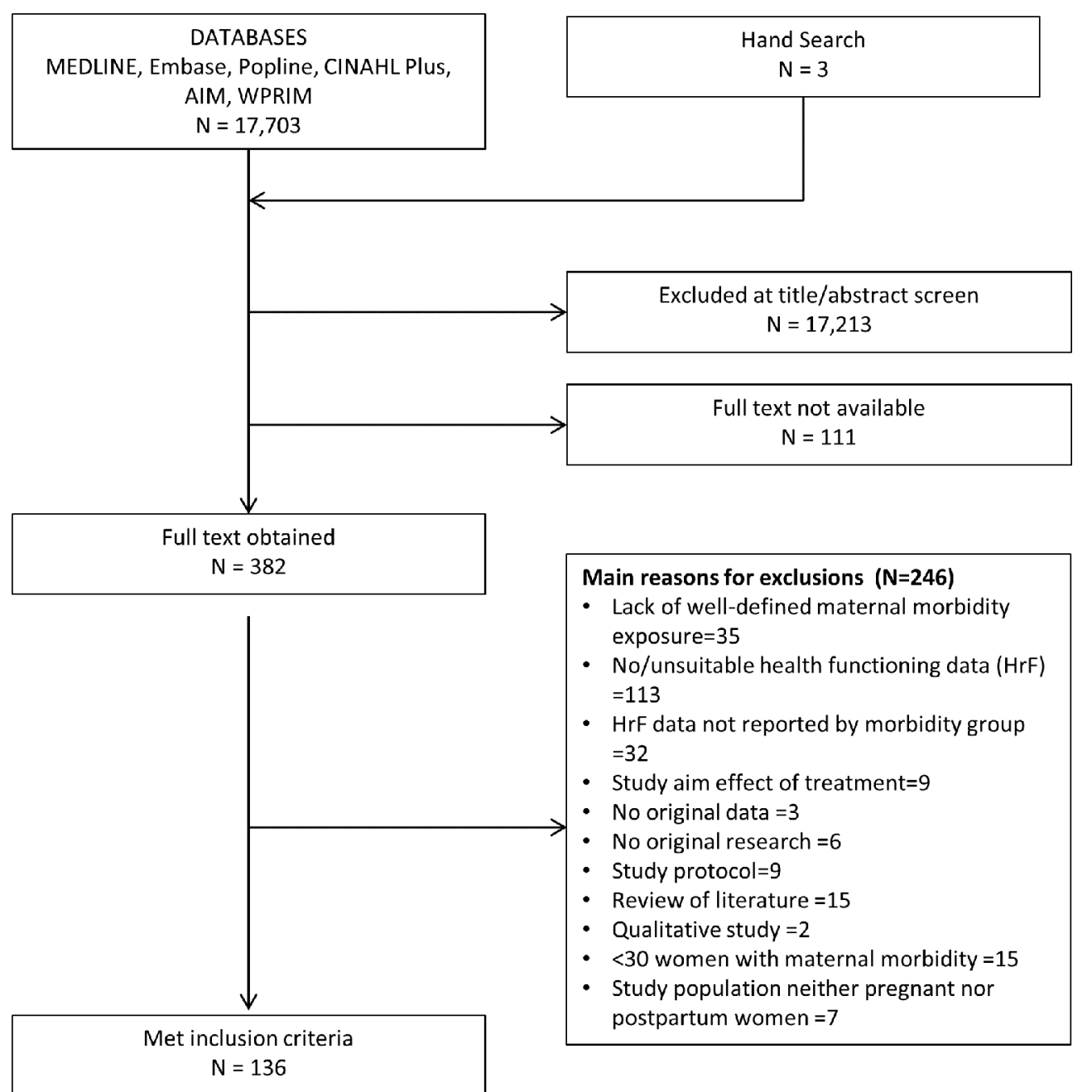

Figure 1 Study selection for inclusion in the systematic scoping review. AIM, African Index Medicus; WPRIM, West Pacific Region Index Medicus. 
times, data of functioning for each health condition and at each time point of observation were extracted. Throughout the reviewing and extraction processes, articles where uncertainty existed were discussed with another reviewer and consensuses reached. Finally, as it is not possible to summarise the results statistically across studies by morbidity because of their differences with respect to research questions, study designs, outcome measures, timing of measurement and control group, two authors (KM, VF) qualitatively assessed each paper to determine the impact of the morbidity on five domains: physical, mental, economic, social and other (see online supplementary appendix 2). If there had been a set of articles that used a given tool to assess impacts of a clearly defined maternal health condition on a well-defined functioning (or dimension(s) of functioning) at a given period among women with similar characteristics, we could have combined the quantitative results and conduct a meta-analysis. Self-reported general health status, maternal, sexual or marital functioning were categorised as 'other' domain. The economic domain was interpreted broadly and included ability to conduct both paid and unpaid work. We relied on authors' interpretations of their study findings when the studies did not have a control or comparison group, or did not provide a statistical test comparing women's functioning between morbid and non-morbid groups. Appraisal of the quality of studies was conducted based on definition of maternal morbidity and health-related functioning, inclusion of relevant controls, sampling methods and completeness of data. Despite a high proportion of poor quality of studies for the purpose of the study, we included all publications relevant to our study aim in this scoping review.

\section{RESULTS}

Our initial database search identified 17706 relevant studies. After screening of titles and abstracts, 382 papers were retained. Of those, we excluded a total of 246 articles after full-text review and data extraction. The main reason for exclusion was lack of well-defined maternal morbidity or health functioning data. Finally, 136 papers were identified for inclusion (figure 1).

Using the classification of maternal morbidity constructed by Chou et al, ${ }^{4}$ the vast majority of the included articles, 84 articles out of $136(62 \%)$, addressed the consequences of indirect causes of morbidity on health-related functioning (see table 1). The studies were concentrated in Europe and North America (56\%, 76 studies), and only 12\% (16 studies) were located in Africa. Health-related functioning in the immediate or extended postpartum period, especially within 1 year of delivery, was more commonly studied, compared with the antepartum period. Cohort study was a particularly common study design. Almost half of the included papers (46\%, 63 studies) did not have a control group.

Table 2 presents distributions of 140 maternal health conditions which were studied as exposures in the 136

\begin{tabular}{|c|c|c|c|}
\hline & $\begin{array}{l}\text { Direct } \\
\text { morbidity } \\
(n=52)(\%)\end{array}$ & $\begin{array}{l}\text { Indirect } \\
\text { morbidity } \\
(\mathrm{n}=84)(\%)\end{array}$ & $\begin{array}{l}\text { Total } \\
(n=136) \\
(\%)\end{array}$ \\
\hline \multicolumn{4}{|l|}{ Region } \\
\hline Africa & 5.8 & 15.5 & 11.8 \\
\hline Asia & 15.4 & 20.2 & 18.4 \\
\hline Europe & 48.1 & 26.2 & 34.6 \\
\hline $\begin{array}{l}\text { Latin America and } \\
\text { the Caribbean }\end{array}$ & 3.8 & 6.0 & 5.1 \\
\hline North America & 13.5 & 26.2 & 21.3 \\
\hline Oceania & 7.7 & 3.6 & 5.1 \\
\hline Multiple & 5.8 & 2.4 & 3.7 \\
\hline \multicolumn{4}{|c|}{ Timing of assessment of functioning } \\
\hline Antepartum & 19.2 & 27.4 & 24.3 \\
\hline $\begin{array}{l}\text { Antepartum and } \\
\text { postpartum }\end{array}$ & 11.5 & 7.1 & 8.8 \\
\hline Postpartum ( $\leq 1$ year) & 26.9 & 42.9 & 36.8 \\
\hline Postpartum (>1 year) & 23.1 & 6.0 & 12.5 \\
\hline $\begin{array}{l}\text { Postpartum (both } \\
\leq 1 \text { year and }>1 \text { year) }\end{array}$ & 7.7 & 11.9 & 10.3 \\
\hline $\begin{array}{l}\text { Postpartum } \\
\text { (unknown) }\end{array}$ & 1.9 & 2.4 & 2.2 \\
\hline Not specified & 9.6 & 2.4 & 5.1 \\
\hline \multicolumn{4}{|l|}{ Study design } \\
\hline Cohort & 63.5 & 40.5 & 49.3 \\
\hline Cross sectional & 23.1 & 41.7 & 34.6 \\
\hline Trial & 7.7 & 15.5 & 12.5 \\
\hline Case-control & 5.8 & 2.4 & 3.7 \\
\hline \multicolumn{4}{|c|}{$\begin{array}{l}\text { Comparison (control) group relevant to maternal } \\
\text { morbidity and functioning }\end{array}$} \\
\hline Yes & 61.5 & 48.8 & 53.7 \\
\hline No & 38.5 & 51.2 & 46.3 \\
\hline Total & 100 & 100 & 100 \\
\hline
\end{tabular}

included articles. The three most frequent maternal morbidity diagnoses studied were mental disorders $(33 \%$, 45 studies), incontinence (12\%, 17 studies) and perineal laceration (9\%, 13 studies). Hyperemesis gravidarum, and nausea and vomiting of pregnancy were studied in nine studies $(6 \%)$. The consequences on health-related functioning of potentially more severe direct obstetric conditions, such as obstetric haemorrhage or severe pre-eclampsia and eclampsia, were not frequently studied. There are limited data on the consequences of puerperal sepsis on health-related functioning except in three nearmiss studies.

Health-related functioning and well-being were measured by applying a number of existing tools (table 3 ). The SF-36 was the most common tool applied and used in 32 studies (22\%). It was particularly common in studies of gestational diabetes and mental disorders. The Short Form 
Table 2 Distribution of maternal conditions

Delivery/termination $(n=7)$

Number of conditions

Percent

Direct maternal morbidity

Gestational trophoblastic disease

$6 \quad 4.3$

Obstructed labour

1

0.7

Hypertensive disorders $(n=7)$

Gestational hypertension

Pre-eclampsia/eclampsia

2

1.4

5

3.6

Obstetric haemorrhage $(n=3)$

Postpartum haemorrhage

2.1

Other obstetric complications $(n=23)$

Gastrointestinal $(n=9)$

Nausea and vomiting of pregnancy

Hyperemesis gravidarum

3 \\ 3}

Endocrine $(n=8)$

Diabetes mellitus (gestational diabetes)

Others $(n=6)$

Deep vein thrombosis

Near-miss*

Multiple obstetric conditions

3

2.1

6

4.3

8

5.7

1

3

0.7

2

2.1

1.4

Unanticipated complications $(n=14)$

Perineal laceration

13

9.3

Spontaneous abortion

1

0.7

Indirect maternal morbidity

Anaemia

3

2.1

Endocrine, nutritional and metabolic diseases $(n=2)$

$\begin{array}{lll}\text { Type } 1 \text { diabetes } & 1 & 0.7 \\ \text { Cystic fibrosis } & 1 & 0.7\end{array}$

Infection ( $n=5$ )

HIV infection

5

3.6

Mental disorders $(n=45)$

Depression

42

30.0

Obsessive compulsive disorder

Multiple

1

0.7

2

1.4

Diseases of the respiratory system complicating pregnancy, childbirth and the puerperium $(n=1)$

Bronchial asthma

1

0.7

Diseases of the genitourinary system $(n=24)$

$\begin{array}{lrr}\text { Urinary/faecal/anal incontinence } & 17 & 12.1 \\ \text { Fistula } & 7 & 5.0\end{array}$

Diseases of the nervous system $(n=2)$

Multiple sclerosis 2

Diseases of the circulatory system $(n=1)$

$\begin{array}{lll}\text { Heart disease } & 1 & 0.7\end{array}$

Diseases of the digestive system $(n=3)$

$\begin{array}{lrr}\text { Enteritis and colitis } & 1 & 0.7 \\ \text { Gastro-oesophageal reflux disease } & 1 & 0.7 \\ \text { Functional intestinal disorders } & 1 & 0.7 \\ \text { Total } & 140 & 100.0\end{array}$

${ }^{*}$ Includes an indirect cause, severe anaemia. 
Table 3 Distribution of maternal conditions by type of tools used in the included studies to measure well-being and functioning

\begin{tabular}{|c|c|c|c|c|c|c|c|c|}
\hline & \multicolumn{8}{|c|}{ Health-functioning tool } \\
\hline & SF-36 & SF-12 & $\begin{array}{l}\text { WHOQOL- } \\
\text { BREF }\end{array}$ & $\begin{array}{l}\text { WHODAS } \\
2.0\end{array}$ & $\begin{array}{l}\text { Disease } \\
\text { specific }\end{array}$ & Own tool & Others & Total \\
\hline Delivery/termination & 0 & 1 & 1 & 0 & 1 & 2 & 2 & 7 \\
\hline Hypertensive disorders & 3 & 1 & 1 & 0 & 1 & 1 & 0 & 7 \\
\hline $\begin{array}{l}\text { Unanticipated } \\
\text { complications }\end{array}$ & 3 & 1 & 0 & 0 & 6 & 2 & 4 & 16 \\
\hline \multicolumn{9}{|l|}{ Indirect maternal morbidity } \\
\hline $\begin{array}{l}\text { Diseases of the } \\
\text { genitourinary system }\end{array}$ & 1 & 0 & 1 & 0 & 13 & 8 & 3 & 26 \\
\hline Other indirect courses & 4 & 0 & 0 & 0 & 6 & 0 & 3 & 13 \\
\hline Total & 32 & 7 & 8 & 2 & 31 & 23 & 45 & 148 \\
\hline
\end{tabular}

Note: 12 studies used more than one type of tool.

SF-12, Short Form 12; SF-36, 36-item Short Form; WHODAS 2.0, WHO Disability Assessment Scale 2.0; WHOQOL-BREF, WHO Quality of Life tool.

12, the WHO Quality of Life tool (WHOQOL-BREF) and WHO Disability Assessment Scale (WHODAS) 2.0 were used in fewer than 10 studies each. Over 30 studies used disease-specific tools. Seventeen studies on incontinence were documented, and the International Consultation on Incontinence Questionnaire Urinary Incontinence Short Form (ICIQ-UI-SF), the Incontinence Impact Questionnaire (IIQ-7), the Faecal Incontinence Quality of Life (FIQL) Score, and the King's Health Questionnaire and Manchester Health Questionnaire were commonly used. While these existing tools were often adopted, many studies applied other tools, especially in studies on mental disorders, including Female Sexual Function Index (six studies), Global Assessment of Functioning (four studies), Perceived Stress Scale (two studies) and Pittsburgh Sleep Quality Index (two studies).

A list of the included articles and the impact of the morbidity on five domains of functioning: physical, mental, economic, social and other, which we assessed for each article, is in online supplementary appendix 2. Among the 136 papers, 116 studies reported negative consequences of maternal morbidity; only 20 articles found no negative impact. There is no maternal health condition for which studies consistently showed no impact on health-related functioning. Physical and mental functioning was frequently assessed, and economic function was rarely studied. Studies of fistulae were often concerned with social, marital and economic domains, and perineal laceration studies often documented sexual functioning. Lastly, environmental factors (facilitators and barriers) of women's functioning were rarely reported in the included papers except for a handful of papers such as those addressing fistulae ${ }^{47-51}$ and near-miss. ${ }^{23}$ Panel 1 and 2 illustrate characteristics of studies of hyperemesis gravidarum and incontinence during pregnancy and the impacts on health-related functioning.

\section{Panel 1: Hypermesis gravidarum}

Hyperemesis gravidarum, a severe and persistent form of nausea and vomiting in pregnancy, affects up to $1.5 \%$ of pregnant women, with an onset at about the fifth week of pregnancy, peaking at 8-12 weeks and usually resolving before the 20th week. ${ }^{52}$ Only five studies examined health-related functioning as a consequence of hyperemesis gravidarum during pregnancy. They were all conducted in high-income countries except for one conducted in Turkey. Existing generic tools were used in three of these studies (Perceived Stress Scale (PSS), Brief Disability Questionnaire and Social Functioning Questionnaire (SFQ)). A disease-specific tool, Hyperemesis Impact Symptoms Questionnaire, was used in one study; and one study did not use any existing tool and researchers created their own items. Despite the different tools used, there was evidence of a significant impact of morbidity on women's daily lives in four studies while one study reported no impact. In a prospective cohort study of pregnant women with and without hyperemesis gravidarum, McCarthy et al applied the PSS and a Behavioural Response to Pregnancy Scale comprising two subscales: limiting/resting behaviour (referring to a tendency to curtail activities of daily living in response to symptoms 
by resting). ${ }^{53}$ Limiting/resting response and PSS scores were higher in women with hyperemesis gravidarum than women without hyperemesis gravidarum after adjusting for possible confounders, such as age, smoking and ethnicity. As the limiting behaviour score normalised several weeks after vomiting ceased, a causal association between hyperemesis gravidarum and deteriorated functioning was suggested in this study. Ezberci et al used the 11-item Brief Disability Questionnaire to assess physical and social disability and showed that the score was higher in women with hyperemesis gravidarum than women without (11.2 vs 8.5) ${ }^{54}$ Power $e t$ al developed and validated the 10-item Hyperemesis Impact of Symptom (HIS) questionnaire to assess how symptoms of hyperemesis gravidarum were impacting women's lives. ${ }^{55}$ The authors showed a significantly higher mean HIS score in women with hyperemesis gravidarum than those without it (16.3 vs 5.6). On the other hand, McCormack et a ${ }^{56}$ used a short 8-item Social Functioning Questionnaire to assess social functioning in different situations (such as at home, work or in relationships) and showed no difference in the Social Functioning Questionnaire scores between women with and without hyperemesis gravidarum, both at around the peak of symptoms and after 26th week when vomiting had ceased. ${ }^{56}$ It was unclear whether the small sample size (32 with hyperemesis gravidarum and 41 without hyperemesis gravidarum) or difference in gestational weeks among the women (hyperemesis gravidarum: 9.66 weeks (95\% CI 8.69 to 10.63 ), non-hyperemesis gravidarum: 12.27 weeks (95\% CI 11.71 to 12.83$)$ ) might have been responsible for the lack of association between hyperemesis gravidarum and impaired social functioning, or whether hyperemesis gravidarum may not have impacted the women's daily functioning. Poursharif et $a \bar{l}^{57}$ presented the type of problems women reported to have experienced as a consequence of hyperemesis gravidarum in a spontaneous response to the question 'how have your life or future plans changed after experiencing hyperemesis?' These included problems with job or school, marital or family relationships and social isolation. ${ }^{57}$ However, while the paper documented the negative psychological and social impacts of hyperemesis gravidarum, the study had important limitations. It did not specifically focus on health-related functioning nor did it use a comprehensive conceptual framework, the online recruitment survey relied on self-referral and self-diagnosis of hyperemesis gravidarum, the duration (since hyperemesis gravidarum onset was not explored) and there was no comparison group.

Hyperemesis gravidarum is an example of a condition for which there is no dominant condition-specific tool. While three studies used generic tools and one study used only its own questions, the condition-specific tool developed by Power et al appears to capture well how hyperemesis gravidarum-associated morbidity impacts key aspects of women's daily life. However, other domains of health-related functioning considered in the review (eg, sexual functioning) were not part of the condition-specific tool.
Panel 2: Faecal and urinary incontinence during pregnancy Incontinence is an example of a condition for which there are existing health-related functioning or QOL tools, developed in the 1990s, and sometimes applied in pregnant and postpartum populations. Faecal or urinary incontinence, that is, involuntary leakage of stool or urine, is a common antenatal condition from which up to $60 \%$ of women suffer during pregnancy. ${ }^{58}$ Anatomical changes such as enlargement of the uterus putting increased pressure on the bladder are responsible. Five studies examined the association between urinary incontinence and health-related functioning during pregnancy, one examined the association with faecal incontinence and another assessed both faecal and urinary incontinence. Three were conducted in high-income countries and four in middle-income countries. Three studies used the ICIQ-UI-SF, which comprised three questions relating to severity of urinary incontinence and one question regarding impact on daily life. However, the studies differ with respect to the research question, study designs, outcome measures and control group.

In a Brazilian study, the mean composite ICIQ score was just above 12. There is no cut-off in the ICIQ score, but a mean score of 12 is considered as severe impact on QOL. ${ }^{60}$ A Nigerian cross-sectional study, which used ICIQ-UI-SF, reported that in $17 \%$ of women, urinary incontinence interfered with daily life. The mean score of ICIQ-UI-SF among 43 women in this study was much lower than in the Brazilian study (4.05). ${ }^{61}$ In a cohort study conducted in Spain, the impact of urinary incontinence was measured using the ICIQ-UI-SF and the percentage of women reporting an impact on daily life was high in each trimester with an upward trend as pregnancies progressed. Similar results were reported in women with double (urinary and anal) incontinence in this study. Another study in Spain, which used IIQ-7, reported no impact on daily life. ${ }^{62}$ The 28 -item, condition-specific Wagner's Quality of Life Scale was used in a cross-sectional study from Turkey and $71 \%$ of women with urinary incontinence reported that it had an impact on their QOL. ${ }^{63}$ Erbil et al developed a 23-item questionnaire based on existing literature to explore the aspects of daily life affected by urinary incontinence in Turkey. ${ }^{58}$ The study found that a large proportion of women were affected by urinary incontinence in some areas of their lives. Particularly affected were: daily activities (75\%), feeling of discomfort $(73 \%)$, liquid avoidance $(53 \%)$, sexual life $(47 \%)$ and isolation from environment $(36 \%)$. Johannessen et al studied faecal incontinence during pregnancy and used the 29-item FIQL which has four subscales. ${ }^{64}$ One quarter of the women in Norway reported that faecal incontinence in late pregnancy affected their behaviour and increased embarrassment. These studies suggest that women's daily lives were negatively affected by incontinence to a great extent. However, because of the use of condition-specific tools in assessing health-related functioning and hence the lack of a comparison 
group, functioning of healthy counterparts was not used as a benchmark in the majority of these studies.

\section{DISCUSSION}

While a substantial number of studies $(n=116)$ have documented mostly negative effects of morbidity on health-related functioning and well-being during pregnancy and after childbirth, the body of evidence is not spread evenly among conditions, domains of health-related functioning or geographically. Most studies focus on indirect conditions such as depression, diabetes and incontinence. The effects of direct obstetric complications, including haemorrhage and pre-eclampsia, have rarely been studied, except for obstetric fistulae linked to obstructed labour, despite their importance in low-income and middle-income countries. The functioning domains studied were also limited, most frequently documenting physical and mental categories; studies of fistulae were often concerned with social, marital and economic domains; and perineal laceration studies often documented sexual functioning. Studies that comprehensively documented all domains, including physical, mental, social, economic, and specifically focused on marital, maternal and sexual limitations, were rare and used their own tools instead of tools previously validated by others. This overall narrow focus on the women's perspective highlights the need for a tool to address the women's health-related functioning more holistically. Furthermore, most of the instruments reviewed have no link with a common data standard such as ICF. This is another reason why the data gathered from the instruments are in data silos, and it is impossible to compare and aggregate data across the studies. Finally, the number of studies, conducted in Africa region, where the morbidity disability-adjusted life years are the highest, is small, with only 16 studies. These mostly concentrated on the effects of fistulae, depression and near-miss complications.

The geographical imbalance in our findings may be due to research in low-income and middle-income countries putting greater emphasis on reducing maternal mortality, which has been a central focus of the Millennium Development Goals (MDGs). ${ }^{65}$ Greater localised interest in mental health and other chronic conditions which affect women over many years, including into menopause, is another reason for the concentration of studies in high-income countries. The proportion of studies on depression is also related to its high prevalence among postpartum women (prevalence from $13 \%$ to $19 \%$ ), ${ }^{8}$ specialised interest by psychiatrists and psychologists, and concerns over its impact on child development. ${ }^{66}$ Urinary incontinence is a very prevalent condition (estimated prevalence of stress urinary incontinence at $41 \%$, ranging from $19 \%$ to $60 \%{ }^{67}$ ) and widely studied. As shown in the current review, urinary incontinence has been found to have negative impact on physical and psychological QOL, but also socioeconomical and sexual well-being of women's lives.
A high proportion of papers were found to be of poor quality for the purpose of this review, as many (46\%) did not have an appropriate control group. The lack of adequate comparison group (such as women without the morbidity of interest, women with uncomplicated childbirth or at the very least women of reproductive age) is problematic when assessing the effects of maternal morbidity. Several cohort studies attempted to circumvent this problem by using the normative findings for their chosen tools available for the general population. However, this is not fully appropriate as pregnant women and women with small babies may be different from the general population and have special circumstances, such as those related to physically carrying a pregnancy and breast feeding their small babies. They may also experience cultural limitations including their ability to leave home and perform the 'normal' activities of healthy adults such as paid and unpaid work. Use of normative findings could also lead to an underestimation of the impact of maternal morbidity, as women who become pregnant are mostly very healthy. ${ }^{68}$ It is these differences from the general population that need further research and a tool based on standardised concepts to provide better, more scientifically sound comparisons among pregnant and postpartum women.

As found in the other systematic review of health-related functioning, ${ }^{29}$ the majority of papers used SF-36. WHOQOL-BREF is also applied to capture QOL. SF-36 is widely used, in view of its longevity (it was created in 1992), its availability (having been translated for use in more than 40 countries) and the accumulated evidence on its psychometric properties for different populations. It allows researchers to compare the impact of a range of diagnoses and conditions, not just obstetric and gynaecological conditions. It is also comprehensive, as it documents general health, physical functioning, mental health, bodily pain, vitality, role limitations because of physical and emotional problems, and social functioning. Several maternal morbidity studies that used SF-36 and WHODAS 2.0 showed a correlation with morbidity, indicating that they have discriminant or predictive validity. Similar correlation was observed with condition-specific tools such as those available for incontinence. However, these generic and condition-specific tools have not been validated among pregnant or postpartum women in different settings. They also do not include maternal functioning, and they do not provide sufficient emphasis on economic, marital and sexual functioning which are important domains for women of reproductive age. Several reviewed studies assessed the consequences of maternal morbidity on the ability to breastfeed and respond to the baby's needs, although they did not assess them in the context of women's functioning. ${ }^{6970}$ This is a particularly important aspect of maternal functioning to investigate.

Therefore, we believe that a health-related functioning tool specific to maternal health should be developed to measure the impact of additional maternal morbidity 
or pregnancy. The tool would contribute to addressing the evidence gap in our knowledge on consequences of maternal morbidity on woman's daily life, and will advocate for the importance in improving the health of women during pregnancy, childbirth and postpartum. The three currently available tools for postpartum populations discussed earlier have limitations as they are either QOL tools with an emphasis on satisfaction or feeling (MAPP-QOL and Mother Generated Index) or have too narrow in scope (IFSAC). The MAPP-QOL tool includes the majority of relevant domains including physical, psychological, social, marital, sexual, economic and maternal functioning, but its focus on satisfaction and areas such as physical appearance and environment makes it unsuitable for measurement of health-related functioning. Ideally, a health-related functioning tool specific to maternal health would be comprehensive (physical, mental, social, economic, marital, sexual and maternal functioning) and should be applicable to conditions that occur during both pregnancy and postpartum periods and comparable across different populations. A new tool specific to maternal health needs to link existing and new functional status measurement instruments to a common data standard and the conceptual framework of the ICF to enable us to compare health-related functioning data across studies.

Inclusion of environmental factors (facilitators and barriers) of women's functioning should also be accounted for in the development of a new instrument specific to maternal health. As noted earlier, disability is the outcome of the interaction with a person with a impairment and the environment. ${ }^{32}$ Level of functioning varies by environmental factors, such as health services, support and attitudes from family members and communities. $^{71}$ Interventions that address women's impairment and personal factors and modify the environment in which women with maternal morbidities live could improve women's health-related functioning in their daily lives.

The main strength of our systematic scoping review is its comprehensive search strategy with 17706 papers screened. However, there are also limitations. While most of the papers found reduced health-related functioning among unwell pregnant or delivered women, this finding could be due to publication bias. As we only considered the published literature and did not review grey literature, we were unable to access the extent to which this was the case. Although we assessed quality of the studies based on definition of maternal morbidity and health-related functioning, inclusion of relevant controls, sampling methods and completeness of data, all publications relevant to our study aim in this scoping review were included. We relied on authors' interpretations of their study results when the studies did not have a control or comparison group, or did not provide a statistical test comparing women's functioning between morbid and non-morbid groups. Therefore, a bias may have been introduced in reporting impact of maternal morbidity on health-related functioning in the studies of poor quality. In addition, we may have overemphasised the degree to which existing tools document economic functions as some of the tools do not specifically address functioning at work, but rather asked about any difficulty in performing work or other regular daily activities to appreciate economic function (eg, SF-36 'During the past 4 weeks, have you had any of the following problems with your work or other regular daily activities as a result of any emotional problems?"). On the other hand, we may have underestimated the number of depression studies documenting maternal dysfunction as we excluded studies of mother-child interactions which did not explicitly address the functionality element. Lastly, while our qualitative approach fit well the objective of our scoping review, a quantitative meta-analysis of the findings to summarise the effects was not possible for any condition, as studies did not use the same analytical approach, tools, measures or timing of assessment for the different conditions under consideration.

\section{CONCLUSION}

While we found ample evidence that maternal morbidity impacts health-related functioning, the available literature does not appear to be sufficiently comprehensive because not all relevant functioning domains are studied and not all complications are studied to the same extent. The development of a scale specifically for maternal health, to be used alongside expansion of existing generic or condition-specific scales, such as WHODAS 2.0, would greatly advance our understanding of the burden of ill health associated with maternal morbidity and facilitate priority setting in maternal health, particularly with respect to its global dimension.

In the transition from the MDG to the Sustainable Development Goal framework, tremendous attention is rightfully being placed upon the need to understand the entire context of maternal health. As countries reduce maternal mortality and improve overall health systems, referred as the 'obstetric transition,' a proportion of maternal morbidity events increases. ${ }^{72}$ The UN Secretary General's Strategy for Women's, Children's, and Adolescent Health, and initiatives such as the EPMM consultations focus direct attention on this phenomenon and call for a holistic approach to improve the health and wellbeing of women, children and adolescents. ${ }^{573}$ The objective is to ensure that all 'survive, thrive, and transform.' With regard to maternal health, it is critical to holistically understand the socioeconomic and environmental determinants that contribute to pregnancy and the spectrum of maternal health-related functioning. To achieve this, we suggest the use of a frequently applied generic tool such as SF-36 and WHODAS 2.0 when comparability with other studies is needed. We also call for more research on the effects of direct complication on health-related functioning. 
Acknowledgements The authors thank José Guiherme Cecatti, Isabelle Lange and other members of the WHO Maternal Morbidity Working Group for thoughtful feedback. We are greatly indebted to Lauren Perieres (LP) for assistance in title and abstract screening, and Andreia Leite, Juliana Cavadas, Benedetta Pongiglione, Yolanda Fernandez, Kim Jeong, Yu He and Maryam Tajvar for translation. This study was presented at the Colloquium on Maternal and Newborn Health Beyond 2015 in Rabat, 25 November 2015, and we are grateful for the comments received.

Contributors Conceived and designed the experiments: VF, DC, LS, KM. Developed the protocol: KM, VF, JAC, AH. Performed the experiments: KM, AH, JAC, VF, MB, DC. Wrote the paper: KM, VF, AH. Commented on and helped revised the manuscript: JAC, DC, MB, NK, LS.

Funding The project described in this article is funded by the Bill and Melinda Gates Foundation and WHO's Department of Reproductive Health and Research through the Special Programme of Research, Development and Research Training in Human Reproduction.

Disclaimer The authors alone are responsible for the views expressed in this article and they do not necessarily represent the views, decisions or policies of the institutions with which they are affiliated.

Competing interests None declared.

Patient consent Obtained.

Provenance and peer review Not commissioned; externally peer reviewed.

Data sharing statement № additional data is available.

Open Access This is an open access article distributed under the terms of the Creative Commons Attribution IGO License (https://creativecommons.org/ licenses/by-nc/3.0/igo/), which permits use, distribution, and reproduction for non-commercial purposes in any medium, provided the original work is properly cited. In any reproduction of this article there should not be any suggestion that WHO or this article endorse any specific organisation or products. The use of the WHO logo is not permitted. This notice should be preserved along with the article's original URL.

(c) Article author(s) (or their employer(s) unless otherwise stated in the text of the article) 2017. All rights reserved. No commercial use is permitted unless otherwise expressly granted.

\section{REFERENCES}

1. Graham W, Woodd S, Byass P, et al. Diversity and divergence: the dynamic burden of poor maternal health. Lancet 2016;388:2164-75.

2. Filippi V, Chou D, Ronsmans C, et al. Level and causes of maternal mortality and morbidity. In: Black RE LL, Walker N, Temmerman M, eds. Disease control priorities 3rd ed vol 2 Reproductive, maternal, newborn and child health. Washington, DC: World Bank, 2016.

3. Stevens GA, Finucane MM, De-Regil LM, et al. Global, regional, and national trends in haemoglobin concentration and prevalence of total and severe anaemia in children and pregnant and nonpregnant women for 1995-2011: a systematic analysis of populationrepresentative data. Lancet Glob Health 2013;1:e16-e25.

4. Chou D, Tunçalp Ö, Firoz T, et al. Constructing maternal morbidity - towards a standard tool to measure and monitor maternal health beyond mortality. BMC Pregnancy Childbirth 2016;16:45.

5. WHO. Strategies toward ending preventable maternal mortality (EPMM)). Geneva: WHO, 2015.

6. GBD 2015 DALYs and HALE Collaborators. Global, regional, and national disability-adjusted life-years (DALYs) for 315 diseases and injuries and healthy life expectancy (HALE), 1990-2015: a systematic analysis for the global burden of disease study 2015. Lancet 2016;388:1603-58.

7. Norhayati MN, Hazlina NH, Asrenee AR, et al. Magnitude and risk factors for postpartum symptoms: a literature review. J Affect Disord 2015;175:34-52.

8. Murray CJ, Barber RM, Foreman KJ, et al. Global, regional, and national disability-adjusted life years (DALYs) for 306 diseases and injuries and healthy life expectancy (HALE) for 188 countries, 1990-2013: quantifying the epidemiological transition. Lancet 2015;386:2145-91.

9. Firoz T, Chou D, von Dadelszen P, et al. Measuring maternal health: focus on maternal morbidity. Bull World Health Organ 2013;91:794-6.

10. Gülmezoglu AM, Say L, Betrán AP, et al. WHO systematic review of maternal mortality and morbidity: methodological issues and challenges. BMC Med Res Methodol 2004;4:16.
11. Haas JS, Jackson RA, Fuentes-Afflick E, et al. Changes in the health status of women during and after pregnancy. J Gen Intern Med 2005;20:45-51.

12. Otchet F, Carey MS, Adam L. General health and psychological symptom status in pregnancy and the puerperium: what is normal? Obstet Gynecol 1999;94:935-41.

13. Wilkins C. Emotional processing in childbirth: a longitudinal study of women's management of emotions during pregnancy and the association with postnatal depression. [PhD thesis]. Bournemouth University 2012.

14. Hueston WJ, Kasik-Miller S. Changes in functional health status during normal pregnancy. J Fam Pract 1998;47:209-12.

15. Tendais I, Figueiredo B, Mota J, et al. Physical activity, health-related quality of life and depression during pregnancy. Cad Saude Publica 2011;27:219-28.

16. Bodhare TN, Sethi P, Bele SD, et al. Postnatal quality of life, depressive symptoms, and social support among women in southern India. Women Health 2015;55:353-65.

17. Cheng CY, Li Q. Integrative review of research on general health status and prevalence of common physical health conditions of women after childbirth. Womens Health Issues 2008;18:267-80.

18. Saurel-Cubizolles MJ, Romito P, Lelong N, et al. Women's health after childbirth: a longitudinal study in France and Italy. BJOG 2000;107:1202-9.

19. Agampodi S, Agampodi T, Wickramasinghe N, et al. Productivity cost due to maternal ill health in Sri Lanka. PLoS One 2012;7:e42333.

20. Storeng KT, Drabo S, Ganaba R, et al. Mortality after near-miss obstetric complications in Burkina Faso: medical, social and healthcare factors. Bull World Health Organ 2012;90:418-25.

21. Assarag B, Dujardin B, Essolbi A, et al. Consequences of severe obstetric complications on women's health in Morocco: please, listen to me!. Trop Med Int Health 2015;20:1406-14.

22. Filippi V, Ganaba R, Baggaley RF, et al. Health of women after severe obstetric complications in Burkina Faso: a longitudinal study. Lancet 2007;370:1329-37

23. Filippi V, Goufodji S, Sismanidis C, et al. Effects of severe obstetric complications on women's health and infant mortality in Benin. Trop Med Int Health 2010;15:733-42.

24. Waterstone M, Wolfe $\mathrm{C}$, Hooper R, et al. Postnatal morbidity after childbirth and severe obstetric morbidity. BJOG 2003;110:128-33.

25. Iyengar K, Yadav R, Sen S. Consequences of maternal complications in women's lives in the first postpartum year: a prospective cohort study. J Health Popul Nutr 2012;30:226-40.

26. Norhayati MN, Nik Hazlina NH, Aniza AA. Functional status of women with and without severe maternal morbidity: a prospective cohort study. Women Birth 2016;29:443-9.

27. Sikder SS, Labrique AB, Shamim AA, et al. Risk factors for reported obstetric complications and near misses in rural northwest Bangladesh: analysis from a prospective cohort study. BMC Pregnancy Childbirth 2014;14:347.

28. Silveira C, Parpinelli MA, Pacagnella RC, et al. A cohort study of functioning and disability among women after severe maternal morbidity. Int J Gynaecol Obstet 2016;134:87-92.

29. Van der Woude DA, Pijnenborg JM, de Vries J. Health status and quality of life in postpartum women: a systematic review of associated factors. Eur J Obstet Gynecol Reprod Biol 2015;185:45-52.

30. Andreucci CB, Bussadori JC, Pacagnella RC, et al. Sexual life and dysfunction after maternal morbidity: a systematic review. BMC Pregnancy Childbirth 2015;15:307.

31. Andreucci CB, Cecatti JG, Pacagnella RC, et al. Does severe maternal morbidity affect female sexual activity and function? evidence from a brazilian Cohort Study. PLoS One 2015;10:e0143581

32. World Health Organization. Towards a common language for functioning, disability and health: international classification of functioning, disability and Health (ICF). Geneval, Switzerland: WHO, 2002.

33. WHOQOL Group. Measuring quality of life: the development of the WOrld Health Organization Quality of Llfe instrunment (WHOQOL). Geneva: WHO, 1993.

34. Bullinger M, Anderson R, Cella D, et al. Developing and evaluating cross-cultural instruments from minimum requirements to optimal models. Qual Life Res 1993;2:451-9.

35. Bowling A. Measuring disease: a review of disease-specific quality of life measurement scales, second edition. Buckingham, Philadelphia: Open University Press, 2001.

36. Cieza A, Stucki G. Content comparison of health-related quality of life (HRQOL) instruments based on the international classification of functioning, disability and health (ICF). Qual Life Res 2005;14:1225-37. 
37. Wilson IB, Cleary PD. Linking clinical variables with health-related quality of life. A conceptual model of patient outcomes. JAMA 1995;273:59-65.

38. Matthews A, Haas DM, O'Mathuna DP, et al. Interventions for nausea and vomiting in early pregnancy. Cochrane Database Syst Rev 2015;9:CD007575.

39. NICE. Clinical guideline: postnatal care up to 8 weeks after birth (CG37). London, 2006 (Last updated 2015.

40. Jomeen J, Martin CR. The factor structure of the SF-36 in early pregnancy. J Psychosom Res 2005;59:131-8.

41. Mogos MF, August EM, Salinas-Miranda AA, et al. A systematic review of Quality of Life measures in pregnant and Postpartum Mothers. Appl Res Qual Life 2013;8:219-50.

42. Fawcett J, Tulman L, Myers ST. Development of the inventory of functional status after childbirth. J Nurse Midwifery 1988;33:252-60.

43. Symon A, McGreavey J, Picken C. Postnatal quality of life assessment: validation of the Mother-Generated Index. BJOG 2003;110:865-8.

44. Hill PD, Aldag JC, Hekel B, et al. Maternal Postpartum Quality of Life Questionnaire. J Nurs Meas 2006;14:205-20.

45. Armstrong R, Hall BJ, Doyle J, et al. Cochrane Update. 'Scoping the scope' of a cochrane review. J Public Health 2011;33:147-50.

46. Say L, Pattinson RC, Gülmezoglu AM. WHO systematic review of maternal morbidity and mortality: the prevalence of severe acute maternal morbidity (near miss). Reprod Health 2004;1:3.

47. Bangser M, Mehta M, Singer J, et al. Childbirth experiences of women with obstetric fistula in Tanzania and Uganda and their implications for fistula program development. Int Urogynecol J 2011;22:91-8.

48. Umoiyoho AJ, Inyang-Etoh EC, Abah GM, et al. Quality of life following successful repair of vesicovaginal fistula in Nigeria. Rural Remote Health 2011;11.

49. Landry E, Frajzyngier V, Ruminjo J, et al. Profiles and experiences of women undergoing genital fistula repair: findings from five countries. Glob Public Health 2013;8:926-42.

50. Muleta M, Rasmussen S, Kiserud T. Obstetric fistula in 14,928 Ethiopian women. Acta Obstet Gynecol Scand 2010;89:945-51.

51. Siddle K, Mwambingu S, Malinga T, et al. Psychosocial impact of obstetric fistula in women presenting for surgical care in Tanzania. Int Urogynecol J 2013;24:1215-20.

52. Bottomley C, Bourne T. Management strategies for hyperemesis. Best Pract Res Clin Obstet Gynaecol 2009;23:549-64.

53. McCarthy FP, Khashan AS, North RA, et al. A prospective cohort study investigating associations between hyperemesis gravidarum and cognitive, behavioural and emotional well-being in pregnancy. PLoS One 2011;6:e27678.

54. Ezberci I, Güven ES, Ustüner I, et al. Disability and psychiatric symptoms in hyperemesis gravidarum patients. Arch Gynecol Obstet 2014;289:55-60.

55. Power Z, Campbell M, Kilcoyne P, et al. The Hyperemesis impact of Symptoms Questionnaire: development and validation of a clinical tool. Int J Nurs Stud 2010;47:67-77.
56. McCormack D, Scott-Heyes G, McCusker CG. The impact of hyperemesis gravidarum on maternal mental health and maternalfetal attachment. J Psychosom Obstet Gynaecol 2011;32:79-87.

57. Poursharif B, Korst LM, Fejzo MS, et al. The psychosocial burden of hyperemesis gravidarum. J Perinatol 2008;28:176-81.

58. Erbil N, Tas N, Uysal M, et al. Urinary incontinence among pregnant Turkish women. Pakistan Journal of Medical Sciences 2011;27:586-90.

59. Spellacy E. Urinary incontinence in pregnancy and the puerperium. $J$ Obstet Gynecol Neonatal Nurs 2001;30:634-41.

60. Oliveira C, Seleme M, Cansi PF, Cd O, Cansi Paula F, et al. Urinary incontinence in pregnant women and its relation with sociodemographic variables and quality of life. Rev Assoc Med Bras 2013;59:460-6.

61. Adaji SE, Shittu OS, Bature SB, et al. Suffering in silence: pregnant women's experience of urinary incontinence in Zaria, Nigeria. Eur J Obstet Gynecol Reprod Biol 2010;150:19-23.

62. Ruiz De Vinaspre Hernandez R, Tomas Aznar C, Rubio Aranda E. [Validation of the Spanish version of the short forms of the urogenital distress inventory (UDI-6) and the Incontinence Impact Questionnaire (IIQ-7) in pregnant women]. Gac Sanit 2011;25:379-84.

63. Kocaöz S, Talas MS, Atabekoğlu CS. Urinary incontinence in pregnant women and their quality of life. J Clin Nurs 2010;19:3314-23.

64. Johannessen HH, Mørkved S, Stordahl A, et al. Anal incontinence and Quality of Life in late pregnancy: a cross-sectional study. BJOG 2014;121:978-87.

65. Nations U. The Millennium Development Goals Report 2015. United Nations, 2015.

66. Murray L, Cooper PJ. Postpartum depression and child development. Psychol Med 1997;27:253-60.

67. Sangsawang B, Sangsawang N. Stress urinary incontinence in pregnant women: a review of prevalence, pathophysiology, and treatment. Int Urogynecol J 2013;24:901-12.

68. Ronsmans $\mathrm{C}$, et al. Evidence for a 'healthy pregnant woman effect' in Niakhar, Senegal? Int J Epidemiol 2001;30:467-73

69. Paris R, Bolton RE, Weinberg MK, et al. Suicidality, and mother-infant interactions. Arch Womens Ment Health 2009;12:309-21.

70. Perez EM, Hendricks MK, Beard JL, et al. Mother-infant interactions and infant development are altered by maternal iron deficiency Anemia. J Nutr 2005;135:850-5.

71. Schneidert M, Hurst R, Miller J, et al. The role of environment in the International classification of functioning, disability and Health (ICF). Disabil Rehabil 2003;25:588-95.

72. Souza JP, Tunçalp Ö, Vogel JP, et al. Obstetric transition: the pathway towards ending preventable maternal deaths. BJOG 2014;121:1-4.

73. Global Strategy for Women's, Children's and Adolescents Health 2016-2030. Every woman every child. New York: Every Woman Every Child, 2015. 
Correction: Consequences of maternal morbidity on healthrelated functioning: a systematic scoping review

Machiyama K, Hirose A, Cresswell JA, et al. Consequences of maternal morbidity on health-related functioning: a systematic scoping review. BMJ Open 2017;7:e013903. doi: 10.1136/bmjopen-2016-013903

The Acknowledgements section for this paper should read:

Acknowledgements We are greatly indebted to Lauren Perieres (LP) for assistance in title and abstract screening, and Andreia Leite, Juliana Cavadas, Benedetta Pongiglione, Yolanda Fernandez, Kim Jeong, Yu He and Maryam Tajvar for translation. This study was presented at the Colloquium on Maternal and Newborn Health Beyond 2015 in Rabat, 25 November 2015, and we are grateful for the comments received. The authors would also like to thank the members of the WHO Maternal Morbidity Working Group for their inputs as well as their overall guidance on the project. Members include (in alphabetical order): Kelli Barbour, Jose Guilherme Cecatti, Sara Cottler, Olubukola Fawole, Tabassum Firoz, Luis Gadama, Atf Ghérissi, Gill Gyte, Michelle Hindin, Anoma Jayathilaka, Amanda Kalamar, Yacouba Kone, Isabelle Lange, Laura A. Magee, Arvind Mathur, Affette McCaw Binns, Mark Morgan, Stephen Munjanja, Gathari Ndirangu Gichuhi, Max Petzold, Elizabeth Sullivan, Frank Taulo, Özge Tunçalp, Rachel VanderKruik, and Peter von Dadelszen.

Correction notice This article has been corrected since it first published. The Open access licence has been changed to an IGO licence.

Open Access This is an open access article distributed under the terms of the Creative Commons Attribution IGO License (https://creativecommons.org/licenses/by-nc/3.0/igo), which permits use, distribution, and reproduction for non-commercial purposes in any medium, provided the original work is properly cited. In any reproduction of this article there should not be any suggestion that WHO or this article endorse any specific organisation or products. The use of the WHO logo is not permitted. This notice should be preserved along with the article's original URL.

C Article author(s) (or their employer(s) unless otherwise stated in the text of the article) 2017. All rights reserved. No commercial use is permitted unless otherwise expressly granted.

BMJ Open 2017;7:e013903corr1. doi:10.1136/bmjopen-2016-013903corr1

Check for updates 